
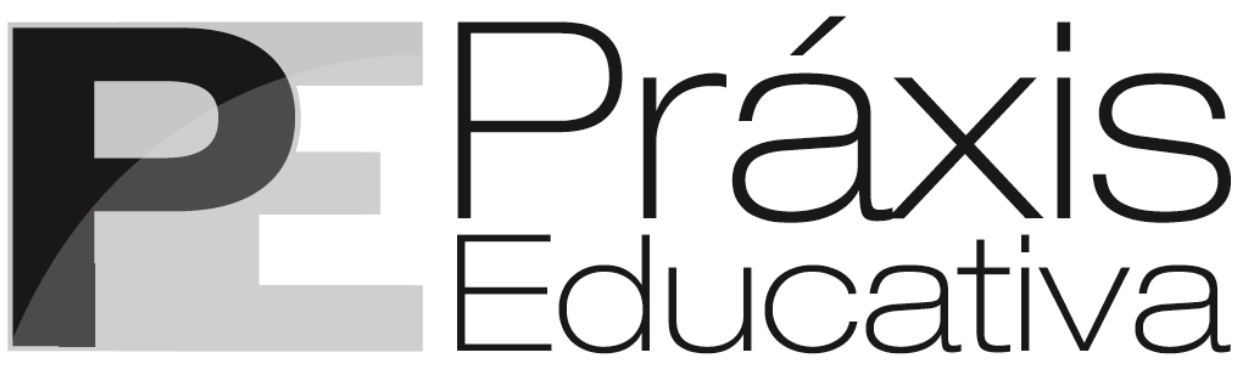

ISSN 1809-4309 (Versão online) DOI: 10.5212/PraxEduc.v.11i3.0013

\title{
Políticas de avaliação na educação básica e seus desdobramentos na disciplina de Arte
}

\section{Evaluation policies in basic education and their developments in Arts as a school subject}

\section{Políticas de evaluación en la enseñanza básica y sus despliegues en la asignatura de Arte}

Silvia Sell Duarte Pillotto* Jane Mery Richter Voigt ${ }^{* *}$

\begin{abstract}
Resumo: Este artigo tem como objetivo identificar como professores da disciplina de Arte se apropriaram das políticas de avaliação e quais foram os desdobramentos dessas políticas nas práticas educativas desses profissionais. De abordagem qualitativa, o instrumento utilizado para coleta de dados foram entrevistas semiestruturadas com professores e estudantes de Arte em escolas da rede pública municipal de ensino. O referencial teórico consiste em documentos oficiais como Diretrizes Curriculares Nacionais Gerais da Educação Básica (BRASIL, 2013), Proposta Curricular de Santa Catarina (SANTA CATARINA, 2014), Lei de Diretrizes e Bases da Educação Nacional (BRASIL, 1996) e ainda Alves (2006), Barbosa (2009), Esteban (2005), Goodson (2001), Hall (2007), Moreira e Candau (2003), entre outros. A análise dos resultados apontou fragilidades no entendimento dos professores sobre os critérios avaliativos, suas conexões com o ensino e aprendizagem e quais políticas de avaliação são assumidas pela escola. Conclui-se que a avaliação é vista pelos professores ora como parte do processo de aprendizagem, ora como elemento limitador, que sinaliza aprovação ou reprovação do estudante e algumas vezes como um fragmento isolado do currículo.
\end{abstract}

Palavras-chave: Práticas educativas. Políticas de avaliação. Arte no Ensino básico.

Abstract: This paper aimed at identifying how teachers of Arts understood the evaluation policies and which were the developments of these policies in their education practice. As a qualitative research, it employed semi-structured interviews with Arts teachers and students in schools of the municipal education system to collect data. The theoretical background comprised official documents such as Diretrizes Curriculares Nacionais Gerais da Educação Básica (General National Curricular Guidelines for Basic Education) (BRASIL, 2013), Proposta Curricular de Santa Catarina (Santa Catarina State Curricular Proposal) (SANTA CATARINA, 2014), Lei de Diretrizes e Bases da Educação Nacional (Education Guidelines and Bases National Law) (BRASIL, 1996) along with the authors Alves (2006), Barbosa (2009), Esteban (2005), Goodson (2001), Hall (2007), Candau (2003), among others. The results pointed to teachers' lack of understanding of the evaluation criteria, their connection with teaching and learning and

\footnotetext{
* Professora da Universidade da Região de Joinville (UNIVILLE). E-mail: <pillotto0@gmail.com>.

** Professora da Universidade da Região de Joinville (UNIVILLE). E-mail: <jane.mery@univille.br>.
}

Práxis Educativa, Ponta Grossa, p. 757-774, v. 11, n. 3, set./dez. 2016 Disponível em: <http://www.revistas2.uepg.br/index.php/praxiseducativa> 
which evaluation policies were adopted by the school. The conclusion was that those teachers sometimes saw evaluation as part of the learning process, other times they saw it as a limiting element, which marked students' approval or failure, and in some situations they saw it as an isolated part of the curriculum.

Keywords: Education practices. Evaluation Policies. Arts in basic education.

Resumen: Este artículo tiene el objetivo de identificar como profesores de la asignatura de Arte se apropiaron de las políticas de evaluación y cuáles fueron los despliegues de esas políticas en las prácticas educativas de esos profesionales. De abordaje cualitativo, el instrumento utilizado para coleta de datos fue entrevistas semiestructuradas con profesores y estudiantes de Arte en escuelas de la red pública municipal de enseñanza. El referencial teórico consiste en documentos oficiales como Diretrizes Curriculares Nacionais Gerais da Educação Básica (BRASIL, 2013), Proposta Curricular de Santa Catarina (SANTA CATARINA, 2014), Lei de Diretrizes e Bases da Educação Nacional (BRASIL, 1996) y aun Alves (2006), Barbosa (2009), Esteban (2005), Goodson (2001), Hall (2007), Candau (2003), entre otros. El análisis de los resultados apuntó fragilidades en el entendimiento de los profesores sobre los criterios evaluativos, sus conexiones con la enseñanza y aprendizaje y cuáles políticas de evaluación son asumidas por la escuela. Se concluye que la evaluación es tomada por los profesores en un dado momento como parte del proceso de aprendizaje y en el otro como elemento limitador, que señala aprobación o reprobación del estudiante y algunas veces como un fragmento aislado del currículo.

Palabras clave: Prácticas educativas. Políticas de evaluación. Arte en la Enseñanza básica.

\section{Introdução}

Muito se tem discutido em eventos científicos, em cursos e encontros de formação e mesmo na escola se é possível avaliar a aprendizagem na disciplina de Arte, se tal fato acontece e de que forma. Com base nessas indagações é fundamental que revisitemos alguns documentos oficiais a fim de compreender essa questão também do ponto de vista da legislação.

Vamos iniciar com a Lei n. ${ }^{\circ}$ 5.692/71, da legislação brasileira, que determinou a inclusão do ensino da Arte na educação básica, nomeada, na época, de Educação Artística. Nesse período, a Arte foi incluída no currículo, porém ainda não era considerada disciplina, pois tinha como objetivo desenvolver habilidades motoras, técnicas de desenho (em especial o geométrico) e a livre expressão. Uma mescla de habilidades que não priorizavam os processos de aprendizagem, a experiência estética e o conhecimento. Um tempo em que a controvérsia se instalava, já que o ensino da Arte estava presente no currículo, porém não como disciplina, apenas como atividade. Nessa abordagem a avaliação era praticamente inexistente, uma vez que não tinha o status de disciplina.

No trajeto histórico de lutas para garantir a permanência do ensino da Arte no currículo, materializa-se a Lei n. ${ }^{\circ}$ 9.394, de 20 de dezembro de 1996, que estabelece as Diretrizes e Bases da Educação Nacional (LDBEN), contemplando a Arte e a Cultura indissociadas, conforme descrito no artigo 26, \2.: "O ensino da arte constituirá componente curricular obrigatório, nos diversos níveis da educação básica, de forma a promover o desenvolvimento cultural dos alunos" (BRASIL, 1996).

O que muda então nas práticas educativas? Apenas a nomenclatura de Educação Artística para Ensino da Arte? A partir da Lei n. ${ }^{\circ}$ 9.394/1996, um novo panorama se instala. A arte é considerada disciplina com conceitos, conteúdos e metodologias próprios.

Nesse momento, os processos de avaliação são incluídos nas práticas educativas, ainda que não no sentido de mensurar se uma produção artística é boa ou ruim ou se um estudante tem mais habilidades do que o outro. Não é tal tipo de julgamento que desejamos, no entanto, como

Práxis Educativa, Ponta Grossa, p. 757-774, v. 11, n. 3, set./dez. 2016 Disponível em: <http://www.revistas2.uepg.br/index.php/praxiseducativa > 
determina a Lei n. ${ }^{0}$ 9.394/1996 em seu artigo 24, V, é necessário que a avaliação seja "contínua e cumulativa do desempenho do aluno, com prevalência dos aspectos qualitativos sobre os quantitativos e dos resultados ao longo do período sobre os de eventuais provas finais" (BRASIL, 1996). Ou seja, acompanhando essas diretrizes, a avaliação na educação básica e no caso, na disciplina de Arte, deve estar mais atenta às condições qualitativas da aprendizagem dos estudantes no que se refere aos conhecimentos ampliados a partir de repertórios artísticos e culturais, bem como a ampliação dos processos de criação, imaginação e percepção.

Também os Parâmetros Curriculares Nacionais - PCN para o ensino da arte (BRASIL, 1998) destacam a importância dos processos qualitativos da Arte ao afirmar que para além do conhecimento como experiência estética por meio da obra de arte, há outros tipos de conhecimentos gerados no universo da arte, tendo como princípio o campo artístico como atividade humana. Esses conhecimentos são trazidos como produto das culturas, parte da História, que são identificadas nos elementos que compõem os trabalhos artísticos, bem como nos princípios que regem sua combinação (BRASIL, 1998).

Portanto, para os PCN (BRASIL, 1998), a avaliação deve levar em conta objetivos e procedimentos didáticos em relação aos conteúdos e aos modos de aprendizagem dos estudantes. No processo de avaliação, o professor precisa considerar a história pessoal de cada estudante e sua relação com as ações desenvolvidas na escola, analisando o registro de suas produções e conhecimentos (BRASIL, 1998).

Independentemente do que o estudante é ou do que pretende ser, a disciplina de Arte está preocupada em propor ações que oportunizem ao cidadão uma formação crítica e sensível. Esse aspecto é reiterado na Proposta Curricular de Santa Catarina (SANTA CATARINA, 2014, p. 111), quando se refere ao ensino da Arte: "uma educação em Arte valoriza o desenvolvimento pleno do ser humano, já que questões como capacidade de percepção e sensibilidade tornam-se fundamentais na educação para experienciar e compreender a realidade social e cultural".

Com base nessas questões, fomos provocadas a desenvolver uma pesquisa na educação básica da rede pública municipal de Joinville com um grupo de dez professores de Arte e dez estudantes, com objetivo de identificar as políticas de avaliação apropriadas pelos professores e seus desdobramentos nas práticas educativas da disciplina em questão. A ideia é refletir sobre essas questões no sentido de qualificar as articulações do ensino e aprendizagem da Arte no currículo. Assim, nosso objetivo com essa pesquisa foi o de identificar também refletir sobre as articulações do ensino e aprendizagem das Artes Visuais no currículo e nas práticas do professor.

No intuito de buscar subsídios para a análise dos dados da pesquisa, fomos à fonte dos documentos oficiais utilizados pela referida rede: Proposta Curricular de Santa Catarina (SANTA CATARINA, 1998), Parâmetros Curriculares Nacionais (BRASIL, 1998), Lei de Diretrizes e Bases da Educação Nacional (Lei n. ${ }^{\circ}$ 9.394/96), Lei n. ${ }^{\circ}$ 5.692, de 11 de agosto de 1971, bem como teóricos do currículo, da avaliação geral e específica da área de Arte.

Além do estudo da legislação, os pressupostos da disciplina de Arte (especificamente no que diz respeito às artes visuais) na educação básica e o aprofundamento teórico nas áreas do currículo e da avaliação foram essenciais para a análise dos resultados das entrevistas semiestruturadas com professores e estudantes. Dessa forma, por meio da análise dos dados da pesquisa, foi possível identificar aspectos relacionados aos processos de ensinar, aprender, avaliar e suas principais dificuldades nesse contexto.

$\mathrm{O}$ artigo segue apontando alguns conceitos sobre currículo, entendendo que o ato de avaliar e ser avaliado está inserido, ou seja, faz parte do currículo. Em seguida, apresentamos

Práxis Educativa, Ponta Grossa, p. 757-774, v. 11, n. 3, set./dez. 2016 Disponível em: <http://www.revistas2.uepg.br/index.php/praxiseducativa> 
discussões referentes às trajetórias curriculares e aos processos avaliativos, do ponto de vista mais geral e específico da área de Arte Visuais. E, na sequência, os movimentos metodológicos e a reflexão sobre as múltiplas falas de professores e estudantes sobre os processos avaliativos. Por fim, trazemos algumas tendências para a avaliação na disciplina de Arte, não como verdade absoluta, mas, sobretudo, como possibilidades.

\section{Dando voz ao currículo}

Em nossa pesquisa entendemos que os processos de avaliação, de ensino e de aprendizagem estão inseridos no currículo. Para isso, alguns teóricos nos auxiliaram na compreensão do que pode ser entendido como currículo e quais os seus desdobramentos.

O termo currículo (curriculum), que nos estudos de Silva (1999, p. 43) contém uma "conotação espacial, 'pista de corrida', local em que os romanos disputavam competições, deriva do verbo 'latino currere', que significa 'correr"'. Para o autor, num sentido renovado, o significado de currículo/curriculum é, antes de tudo, um verbo, uma atividade, e não um substantivo. Nesse viés, a escola e o currículo são responsáveis por determinar formas de se perceber e pensar o espaço, o tempo e as identidades; essa percepção e entendimento não são naturais, mas sim construídos historicamente pelas culturas e pela sociedade.

Circulando pelos territórios da educação, das culturas e do currículo, observa-se que existe uma relação profunda entre educação e cultura, seja compreendendo o termo educação em sentido amplo, de formação e socialização do sujeito durante toda a vida, seja no âmbito do domínio escolar.

Segundo Veiga-Neto e Wortmann (2001), a perspectiva "monocultural" é questionada, principalmente pelos campos da antropologia, da filosofia, da sociologia e da linguística, uma vez que defendem o entendimento de "culturas" em vez do universalismo da cultura, considerando, assim, o caráter multicultural das sociedades contemporâneas.

Na visão de Moreira e Candau (2003), há que se considerar a centralidade das questões culturais no cenário contemporâneo, especialmente no currículo. Para os autores, a ideia de centralidade da cultura, com base nas ideias de Stuart Hall (2007), refere-se exatamente à forma como a cultura penetra em cada recanto da vida social contemporânea, tornando-se elementochave no modo como o cotidiano é configurado e modificado.

Nesse sentido, as relações entre escola e cultura não podem ser compreendidas como polos independentes, mas como universos entrelaçados, já que a escola constitui uma instituição cultural. Na atualidade, a escola não pode ser apenas uma instituição que transmite a "verdadeira cultura"; ela se torna um espaço de cruzamentos de diferentes culturas, consequentemente, um espaço de conflitos e diálogos entre culturas.

De acordo com Goodson (2001, p. 42), "a escola deveria procurar tratar de igual modo todos os grupos diferentes quer estejam estratificados por processos sociais, gênero ou raça". $\mathrm{Na}$ percepção do autor, "[...] a introdução das disciplinas na escola não é uma decisão racional e desapaixonada sobre as coisas que se considera serem de interesse para os alunos. É um ato político concebido de uma forma muito mais global", em que todos os grupos deveriam ter voz, o que entendemos como democracia e autonomia (GOODSON, 2001, p. 41).

Outro aspecto da organização curricular apontado por Macedo (2002) diz respeito à seleção dos conteúdos que fazem parte do currículo escolar. Essa organização segue uma configuração tradicional de conhecimentos agrupados e organizados por disciplinas ou matérias 
escolares. As disciplinas “[...] escolares são grandes classes segundo as quais se agrupam alguns saberes que penetram na escola. Os critérios de criação dessas classes e de inserção de um determinado saber nessa ou naquela classe são sempre históricos [...]" (MACEDO, 2002, p. 50).

Para Petitat (1994), existem múltiplos sentidos na contribuição da escola para a produção social, pois ela participa ativamente das transformações nas estruturas dos grupos sociais, com consequências decisivas no processo de produção e reprodução cultural. Ainda, para o mesmo autor, a escola é uma articulação seletiva de conjuntos culturais e grupos sociais e, portanto, participa tanto da produção quanto da reprodução da sociedade e da cultura.

Porém toda educação, especialmente a escolar, pressupõe uma seleção e uma reelaboração dos conteúdos a serem mediados. Conforme Forquin (1993), a educação não transmite "a cultura" considerada patrimônio único e coerente, mas "algo da cultura", ou elementos das culturas não homogêneas e uniformes, abarcando uma diversidade irregular e mesmo vulnerável em seus modos de transmissão. Nessa perspectiva, compreende-se o currículo como uma porção da cultura: "[...] a escola não ensina senão uma parte extremamente restrita de tudo o que constitui a experiência coletiva, a cultura viva de uma comunidade humana" (FORQUIN, 1993, p. 15).

Também para Forquin (1993) as relações entre educação e cultura são inquestionáveis. Para o autor, existe uma relação profunda entre ambas, seja na concepção ampla de educação como formação e socialização dos sujeitos, seja no âmbito específico da educação escolar. Do mesmo modo, a função de produção e transmissão cultural da educação refere-se a um patrimônio de conhecimentos, de valores, de símbolos, da cultura compreendida como herança coletiva e patrimônio intelectual.

Com base nessas considerações, vale refletir sobre a afirmação de Morgado (2007, p. 53), que aponta a necessidade de rever e (re)significar o currículo nas escolas. Caso contrário, diz ele, "corremos o risco de continuarmos a centrar-nos nos conteúdos e no ensino e a restringir os processos educativos à mera transposição de saberes teóricos oriundos do terreno das disciplinas". Fala ainda sobre a urgência de "desenvolver e consolidar uma cultura de participação e de colaboração no seio de cada instituição, capaz de tornar permeáveis os campos disciplinares e de promover dinâmicas de abordagem inter e multidisciplinar de saberes" (MORGADO, 2007, p. 53).

Nesse viés, Alves (2006) salienta a importância de um equilíbrio entre a apropriação de conhecimentos que devem ser selecionados com responsabilidade, e o comprometimento por parte dos protagonistas envolvidos. Nesse conjunto há que se pensar no desenvolvimento das capacidades transversais "[...] e um desenvolvimento de competências, mais objetivas, centradas nas aquisições de todos os tipos: conhecimentos, capacidades, automatismos, atitudes, aquisições da experiência" (ALVES, 2006, p. 177).

Um currículo, segundo Pimentel (1999), especialista na área de Arte/Educação, explicita as complexas relações entre conhecimento e sociedade, uma vez que a educação institucionalizada condensa o que diferentes grupos sociais refletem e o modo como projetam suas visões e expectativas. As questões do currículo, portanto, não se reduzem aos aspectos técnicos, e sim configuram-se em questões culturais no sentido mais amplo e complexo que constituem a sociedade contemporânea. 


\section{Processos avaliativos na disciplina de Arte}

Numa perspectiva curricular, ao tratar especificamente sobre a avaliação na disciplina de Arte, sentimos necessidade de buscar autores que têm desenvolvido pesquisas específicas nessa abordagem. Destacamos, então, Eisner (1998), que em seus estudos defende a avaliação no ensino da Arte vinculada ao contexto sociocultural dos estudantes. O autor defende ainda que os processos de aprendizagem só acontecem quando o estudante percebe as relações entre o que é ensinado e avaliado com o que é vivido por ele.

Também Boughton (2005) se refere à avaliação na disciplina de Arte, especialmente quando destaca que a avaliação deve ser um processo democrático com ênfase no desenvolvimento cognitivo, perceptivo e sensível do discente. Rompe com a ideia de avaliação redutora e fragmentada, apontando para uma avaliação narrativa que dá voz às vivências e aos conhecimentos dos estudantes.

Nos processos históricos que envolvem a avaliação na disciplina de Arte, é possível observar alguns equívocos e alguns avanços. Numa abordagem tradicional, o produto final ganha destaque em detrimento aos processos sensíveis e estéticos. A apreciação da obra de Arte, o belo e a perfeição são requisitos básicos para que os estudantes tenham boas notas. Tal tendência reduz os processos de aprendizagem e exclui aqueles estudantes considerados "sem talento". Portanto, a avaliação nessa abordagem leva em conta o talento, a qualidade técnica e produções de cunho figurativo (SANTA CATARINA, 1998).

Numa abordagem tecnicista, a quantidade de atividades com técnicas variadas é sucesso certo do professor de Arte e as produções em série garantem as boas notas dos estudantes. Essa perspectiva conduz para um ensino e aprendizagem fragmentado e descontextualizado, culminando com um professor de Arte perdido no meio de tantas abordagens técnicas e quantitativas e com estudantes desmotivados e desencantados com as aulas de Arte. A avaliação nessa tendência leva em conta a precisão técnica, acabamento e quantidade de produções (BARBOSA; COUTINHO, 2009).

$\mathrm{Na}$ livre expressão, o crédito fica por conta apenas do processo, ignorando-se completamente a produção artística, o conhecimento apropriado pelos estudantes, entre outros aspectos. Verificamos que nessa tendência ainda existem resquícios das abordagens tradicionais e tecnicistas, criando um espaço para equívocos e confusões por parte do professor de Arte. $\mathrm{Na}$ avaliação, levam-se em conta a "participação" do estudante e o "envolvimento" nas atividades artísticas. As aprendizagens em Arte não são priorizadas e o professor prima pelo bem-estar de todos. Essa postura também reduz as possibilidades de aprendizagem em Arte dos estudantes, que poderiam ampliar seus conhecimentos e incorporar a Arte como parte de seu cotidiano.

Atualmente evidenciamos alguns avanços no que tange à avaliação na disciplina de Arte, embora não possamos negar as influências e os resquícios das tendências passadas (tradicional, tecnicista e livre expressão).

Vale destacar que esses processos históricos estão atrelados às políticas de avaliação, inseridas em documentos oficiais, como Leis de Diretrizes e Bases da Educação Nacional, propostas e diretrizes curriculares e políticas públicas educacionais. Por essas razões, consideramos importante ouvir professores de Arte e seus alunos a fim de investigar os avanços, ou não, diante das políticas, especialmente no que se refere aos processos de avaliação. 


\section{Movimentos metodológicos}

A presente investigação de abordagem qualitativa teve como campo cinco escolas de educação básica da rede pública municipal de Joinville, Santa Catarina, com um grupo de dez professores de Arte Visuais (dois em cada escola) e dez estudantes do ensino fundamental (um estudante do $6^{\circ}$ ano e um do $9^{\circ}$ ano em cada escola).

A escolha por cinco escolas, dez professores de Artes Visuais e dez estudantes do ensino fundamental, deve-se principalmente pelo reduzido número de professores de artes visuais em função da reduzida carga horária. Com relação a nossa escolha por estudantes do ensino fundamental, a ideia foi perceber diferentes abordagens dos professores de artes visuais, bem como diferentes impressões dos estudantes sobre os processos de ensino e aprendizagem e avaliação dessa disciplina.

As questões abordadas nas entrevistas semiestruturadas com os professores de Arte Visuais foram: $O$ que é avaliado na disciplina de Arte? São estabelecidos critérios de avaliação? Esses critérios são definidos e discutidos em conjunto com os estudantes? A avaliação é retomada com os estudantes? Quais ações são desenvolvidas para reverter questões-problema nos processos de aprendizagem e consequentemente na avaliação? Quais as maiores dificuldades no processo de avaliação? Quais políticas de avaliação são apropriadas pela escola e na sua prática? A partir dessas questões buscamos identificar as conexões entre avaliação, ensino e aprendizagem, bem como desdobramentos nas suas práticas educativas.

Para os estudantes as questões abordadas nas entrevistas foram: como você é avaliado na disciplina de Arte? É claro para você sobre o que é avaliado na referida disciplina? O professor retoma a avaliação? De que forma? São definidas ações para questões-problema com relação aos processos de aprendizagem e de avaliação pelo professor? Você se sente satisfeito com os processos de avaliação na disciplina de Arte? Tem sugestões a fazer? As questões puderam sinalizar as concepções e encaminhamentos também referentes à atuação do professor no que diz respeito aos processos de ensino, aprendizagem e avaliação. No entanto, esse é um tempo que enfrentará sempre variáveis e aspectos incompletos.

Vale ressaltar que durante todo o período das entrevistas as pesquisadoras levaram em conta as especificidades do ambiente, dos sujeitos e também os aspectos culturais. Buscamos nos despir de ideias preconcebidas ou de teorias fechadas sobre processos avaliativos, isso porque para nós é fundamental que haja uma relação de confiança e afeto entre pesquisadores e protagonistas de uma pesquisa. Essa característica é própria, segundo Minayo e Sanches (1993, p. 244), de uma pesquisa qualitativa que

[...] realiza uma aproximação fundamental e de intimidade entre sujeito e objeto, uma vez que ambos são da mesma natureza: ela se volve com empatia aos motivos, às intenções, aos projetos dos atores, a partir dos quais as ações, as estruturas e as relações tornam-se significativas.

Para nós, também foi fundamental e elemento balizador a revisão bibliográfica, pois além de ser imprescindível numa pesquisa, é aspecto essencial no processo de produção de novos conhecimentos e na construção do objeto de pesquisa na área escolhida (ALVES, 2006).

O acesso à literatura específica sobre avaliação e avaliação em Arte inserida no currículo, bem como os estudos sobre currículo, contribuiu tanto nas questões conceituais e teóricas da pesquisa como nos processos metodológicos. Também a leitura de documentos oficiais nos permitiu perceber que na maioria das vezes eles são interpretados e apropriados pelas redes públicas, escolas e professores com variáveis bastante distintas do que realmente apresentam.

Práxis Educativa, Ponta Grossa, p. 757-774, v. 11, n. 3, set./dez. 2016 Disponível em: < http://www.revistas2.uepg.br/index.php/praxiseducativa> 
Numa pesquisa qualitativa, é preciso, além dos estudos e da apropriação do conhecimento, saber lidar com os significados sociais e subjetivos considerando "que pontos de vista e práticas no campo são diferentes devido às diversas perspectivas subjetivas e ambientes sociais a eles relacionados" (FLICK, 2004, p. 22). Nessa vertente, segundo Gatti e André (2010, p. 30), numa pesquisa qualitativa deve ser

[...] dada especial atenção ao mundo do sujeito e aos significados por ele atribuídos às suas experiências cotidianas, às interações sociais que possibilitam compreender e interpretar a realidade, aos conhecimentos tácitos e às práticas cotidianas que forjam as condutas dos atores sociais.

Portanto, a pesquisa evidenciou a fala dos professores de Arte e estudantes, que foram transcritas na íntegra, com o intuito de que pudéssemos interpretar quais as relações desses professores e estudantes com os processos avaliativos. Em nossa abordagem metodológica a narrativa foi fundamental, uma vez que se espera por meio dela compreender os relatos de experiência dos entrevistados, extraindo o máximo possível a sua essência.

\begin{abstract}
Nestes termos, a fala torna-se reveladora de condições estruturais, de sistemas de valores, normas e símbolos (sendo ela mesma um deles) e, ao mesmo tempo, possui a magia de transmitir, através de um porta-voz (o entrevistado), representações de grupos determinados em condições históricas, socioeconômicas e culturais específicas. (MINAYO; SANCHES, 1993, p. 13).
\end{abstract}

Pretende-se entender por intermédio das falas dos professores e estudantes o jogo intrínseco de significados e o teor do que está sendo dito - a essência da narrativa, dada pelos entrevistados.

Portanto, com base nos dizeres de professores de Arte e dos estudantes, pudemos evidenciar conflitos e inquietudes com relação aos processos avaliativos e também equívocos conceituais e desvinculação da avaliação com o currículo. Esses fatores, juntos, sinalizam certa negação com a avaliação e outras vezes apatia, pois ainda há resquícios de que na disciplina de Arte não se ensina e não se aprende. Está no currículo apenas como uma possibilidade de extravasar sentimentos, especialmente os que trazem prazer e alegria.

\title{
Refletindo sobre as múltiplas vozes
}

Nas questões sobre o que é avaliado na disciplina de Arte, 100\% dos professores manifestou o produto final como prioridade. Interessante ressaltar que essa produção tem como foco ainda a "releitura" de imagens e "provas", principalmente sobre textos referentes à biografia de artistas.

$\mathrm{Na}$ voz dos professores, "ainda estou na releitura..." (Prof a D); “[...] passo o conteúdo teórico, vamos supor, a biografia de um artista ou de um estilo de arte, então en 'cobro' esse conhecimento" (Prof ${ }^{\circ}$. E). Essas questões são ainda reforçadas na fala de um dos estudantes: "[...] a professora põe no quadro pra gente poder 'copiar' ou 'fazer igual' às gravuras que ela traz e a história dos desenhos" (estudante E - 5. série. Grifos nossos).

Nos depoimentos percebe-se um hiato muito grande entre as concepções contemporâneas do ensino da Arte e as práticas no contexto escolar. A abordagem adotada pela maioria dos professores é operacional, cujos conteúdos são desenvolvidos de forma fragmentada, sem conexão entre o fazer, o ler, o contextualizar e o refletir. Além disso, releitura, para esses professores, resume-se à atividade de cópia; leitura é entendida apenas como descrição e a contextualização se limita a apresentar a biografia do artista.

Práxis Educativa, Ponta Grossa, p. 757-774, v. 11, n. 3, set./dez. 2016 Disponível em: < http://www.revistas2.uepg.br/index.php/praxiseducativa > 
Essa foi e é uma prática ainda contraditória, uma vez que esse termo tem sido socializado numa outra perspectiva por educadores em arte, a exemplo de Pillar (2006). Tal contradição diz respeito especialmente ao entendimento de alguns professores de que releitura é uma cópia fiel, ou quase fiel da imagem de obra de arte observada. Para Pillar (2006, p. 18), "[...] a cópia diz respeito ao aprimoramento técnico, sem transformação, sem interpretação, sem criação".

A tentativa da cópia pode aprisionar os processos de leitura do estudante, determinando significados fechados, ou seja, pode tornar-se uma ação meramente técnica sem acrescentar ao pensamento estético o prazer de criar e de relacionar aquilo que vê ao seu contexto, as suas impressões sobre a vida. Portanto, a releitura na visão da autora implica uma reconstrução e ressignificação na construção de uma nova materialidade com novos sentidos.

Ainda para Pillar (2006), há que se considerar diferenças e convergências entre leitura e releitura. Entende-se como leitura uma atividade reflexiva/teórica sobre as imagens, e releitura é ação prática de interpretação/ressignificação e, consequentemente, reconstrução de uma obra/objeto. "Reler é ler novamente, é reinterpretar, é criar novos significados" (PILLAR, 2006, p. 18).

No contexto das aulas de artes, as práticas de leituras e releituras de obras/objetos de arte poderiam ser tomadas como encontros intensivos com as coisas, fecundando ressonâncias entre artistas e expectadores e promovendo a ação criadora dos estudantes. Nessa perspectiva, interpretar é reinventar, imaginar, fantasiar e falsear. Não se nega o ato de interpretar, mas sim as imposições de sentido que os discursos prontos sobre a arte produzem. A multiplicidade de leituras e releituras leva à ação criadora. Criar vem a ser um ato de liberdade. As práticas de sala de aula como um todo abrem espaço para a criação, proliferando tanto as conexões quanto as disjunções na invenção da novidade. Como modo de pensar, a arte busca criar variações. Podemse ensinar técnicas, formas de expressão diferentes, circunstâncias históricas que envolveram certos modos de expressão plástica, todavia a arte, enquanto criação, não se ensina, faz-se, vivese, pois pressupõe a experiência.

Ao relatar o processo de avaliação, tanto professores quanto estudantes apontaram que: quanto mais próximo à cópia fiel, melhor a nota. Quanto mais os estudantes sabem sobre a biografia dos artistas (em exercícios ou provas), melhores notas terão. Ou seja, a avaliação é quantitativa e prioriza a reprodução e a memorização. Cabe, então, o questionamento: quais as alternativas possíveis para que possamos romper com essas concepções, avançando para uma avaliação qualitativa, que valorize os processos de aprendizagem e a construção de saberes em Arte?

Verificamos um descompasso nas falas, especialmente entre o professor e as Diretrizes Curriculares Nacionais Gerais da Educação Básica (BRASIL, 2013, p. 52), quando determina que "[...] é preciso adotar uma estratégia de progresso individual e contínuo que favoreça o crescimento do estudante, preservando a qualidade necessária para a sua formação escolar".

Entre as muitas propostas para o ensino da Arte contemporâneo, Hernández (2007) tem defendido a ideia de que o estudante, ao fazer relações entre imagens, objetos, artefatos vinculados às experiências culturais, aprende a elaborar/criar narrativas visuais. Trata-se de um dos caminhos possíveis, aliado a nossa inserção nas políticas públicas para que as mudanças recorrentes na educação de uma forma geral também possam acontecer.

Sobre os critérios de avaliação, os professores citam como importante: acabamento, capricho, limpeza, criatividade, participação, comportamento/disciplina, interesse, pontualidade na entrega dos trabalbos. Nas falas dos professores percebemos que os critérios, na sua maioria, são de natureza 
comportamental, em detrimento da apropriação de conhecimentos em Arte. O professor D afirma: "[...] o que entra muito é a participação do aluno, a disciplina deles, o comportamento deles em sala de aula e também o interesse do aluno". Também os estudantes, quando questionados sobre como são avaliados: "[...] através do comportamento que nós temos nessa aula e os trabalhos, a profe passa um texto e depois trabalha com os artistas" (Aluno D - 6. " série).

Esses relatos remetem a uma avaliação classificatória como forma de manipulação de sujeitos. Segundo Estebán (2005), esse tipo de avaliação se traduz como um conjunto de práticas sociais que tomam o conhecimento como meio de manipulação e forma de dominar o mundo. $\mathrm{O}$ foco está muito mais no rendimento e comportamento como resultado final, ou seja, inscreve-se nas práticas sociais cujo objetivo é o mecanismo de vigilância e punição.

Quanto ao item da entrevista sobre a socialização dos critérios com os estudantes, $90 \%$ dos professores afirmam não socializar os critérios de avaliação; $10 \%$ o fazem parcialmente. No entanto, com relação à retomada e recuperação de notas, 100\% dos professores diz que propõe recuperação, dando oportunidade para que os estudantes refaçam suas produções, recuperando a sua nota. Nas palavras do Prof. E: "Tento seguir os PCN no que diz respeito à avaliação, mas é praticamente impossivel nessa escola, porque quando os alunos têm problemas e ganham nota baixa o pai que vem na escola reclamar... A direção acha que o professor é o culpado e chega a questionar o que é abordado para acontecer tal situação...”.

O problema referenciado pelo professor E está presente na fala estudante B: "as vezes essa aula é complicada...não entendo muito bem o que a profe quer! Às vezes parece que ela quer tudo bonitinho e colorido e às vežes diz que está muito certinho, que épreciso deixar mais abstrato, dá para entender?"

Importante destacar, como dito na Proposta Curricular de Santa Catarina (2014, p. 102) que a função da arte no currículo tem como finalidade o contato do sujeito com artefatos de diferentes culturas, possibilitando "[...] o conhecimento relacional de si próprio, a vivência de diferenças, a potencialização do senso crítico, a reflexão sobre o sentido de pertencimento, além do conhecimento de novas culturas e história de outros povos".

Porém, na fala do professor E é possível perceber claramente que existe uma mentalidade cristalizada, não apenas pelo professor e pela direção, mas também pela família e comunidade de forma geral, de que a disciplina de Arte é puro lazer apenas. Evidentemente que ao abordar nas práticas educativas as questões da arte/cultura, entramos por vezes no universo da experiência estética e do saber. Entretanto, essas questões muitas vezes são ignoradas em detrimento de uma visão reducionista do entendimento do ensino da Arte como "perfumaria", ou seja, compreendendo-a como dispensável para o desenvolvimento humano, vendo-a apenas como entretenimento. Com isso, perde-se então o pensamento estético/reflexivo, tão importante para a construção de um sujeito crítico/sensível.

Uma das principais funções do ensino da arte na educação básica como apontam Ferraz; Fusari (2009, p. 58) é o diálogo com todas as culturas e formas de arte, perpassando do erudito ao popular. Assim espera-se que os conteúdos sejam sistematizados "a partir de eixos norteadores de aprendizagem, a saber: produção em arte - desenvolvimento do percurso de criação pessoal; fruição - apreciação significativa da arte e reflexão sobre a arte enquanto produto pessoal e pertencente à multiplicidade, de todas as épocas”.

Outro aspecto que pode ser problematizado, encontra-se na fala do estudante E, quando verificamos certa confusão em relação ao comando do professor. Fica claro que a avaliação parte especialmente do gosto do professor, que também oscila entre o figurativo e o abstrato. $\mathrm{O}$ preocupante é que não estão presentes critérios relativos aos processos cognitivos e/ou sensíveis. 
Não está em jogo o que o estudante aprendeu, mas a sua produção voltada unicamente para o que o professor considera aceitável, ou seja, ora um trabalho figurativo e colorido, ora algo abstrato.

Outro aspecto a ser considerado é a oscilação das avaliações dos estudantes. Os professores alegam que num bimestre está tudo bem e no outro percebem um baixo rendimento. Essa questão traz à tona as considerações do professor E e as do estudante B. Parece-nos que nos bimestres em que o estudante "vai bem" são cumpridos os paradigmas do professor em relação ao que ele considera bom; no bimestre em que o estudante "vai mal" os paradigmas do professor não foram cumpridos - atividades bem acabadas, coloridas, figurativas ou, na outra ponta, abstratas! Então fica a dúvida: como tem sido tratada a avaliação em Arte? De forma integrada ou fragmentada? Avalia-se produção artística? Conteúdos teóricos? A trajetória de aprendizagem do estudante? Para Martins, Picosque e Guerra (2009, p. 134), a avaliação é um processo que envolve a leitura dos estudantes, do professor e dos conteúdos abordados e reinterpretados constantemente, "[...] fornecendo um mapa dos interesses e das necessidades da turma. É ponto de chegada e de partida, é meio, começo, fim e reinício. É um jeito de acompanhar a processualidade dos movimentos feitos no encontro pedagógico".

Também para Ferreira e Boff (2009, p. 94) é fundamental que o professor acompanhe as aprendizagens dos estudantes, auxiliando-os na superação das dificuldades. Isso exige do "[...] professor uma proximidade com o percurso do aluno, visto que a avaliação não está associada a um momento específico, mas ao decorrer de todo o processo".

No tocante ao percurso de professor e estudantes, encontram-se os critérios de avaliação, que nas vozes dos professores entrevistados são flutuantes, muito pouco articulados com os processos de ensino e de aprendizagem. Vale dizer que, embora possa parecer que os critérios pensados pelos professores não tenham qualquer ligação com os processos de ensinar e aprender, é necessário compreender que os "critérios de avaliação não surgem do nada. São frutos de uma sociedade, de uma ideologia, de determinada visão de mundo, de uma época ou país; cada um refletindo práticas, teorias e concepções pedagógicas diferentes" (MARTINS; GUERRA, 1998, p. 142). Assim, podemos presumir que a seleção de critérios avaliativos está atrelada aos conhecimentos e às vivências do professor, apropriados na sua formação, bem como nas suas práticas educativas, seus processos de criação, seus interesses, desejos e vontade de aprender coletivamente.

Também é importante considerar, como afirma Sant’Anna (2010, p. 78), que os critérios de avaliação são na maioria das vezes determinados pelo sistema educacional ou subsistema, “[...] embora o mais comum é que cada escola, através de seu regimento, registre os critérios ou normas a serem observados pelos responsáveis das diferentes disciplinas curriculares".

Ficou clara na fala dos professores a desvinculação dos critérios avaliativos com a prática da recuperação, que está centrada na repetição do conteúdo para os estudantes que não conseguiram alcançar a média $(7,0)$. No entanto não há uma conscientização da necessidade de uma abordagem diferenciada para que os estudantes possam aprender o que não aprenderam. Assim, a recuperação é praticamente inútil, pois a lógica continua a mesma e, portanto, os alunos continuam não aprendendo. Quando conseguem a média necessária, é porque fizeram um trabalho orientado ou memorizaram provas anteriores com as respostas corretas.

É preciso romper com esses modelos e pensar em processos de avaliação em artes visuais que levem em conta a aprendizagem desse campo de conhecimento, tendo em vista que conceitos, conteúdos, metodologias e avaliação, mais do que promover resultados e 
comportamentos, pretendem a apropriação de conhecimentos, fundamentais para a construção humana.

Sobre as dificuldades encontradas nos processos de avaliação na disciplina de Arte, os professores apontam os seguintes itens: ausência de livros especificos em Arte nas bibliotecas das escolas; falta de sala ambiente para o ensino da Arte (95\% das escolas públicas no município não possuem sala específica para Arte); falta de materiais, excesso de estudantes em sala (média de 45) e, como a maior dificuldade apontada por $100 \%$ dos professores entrevistados, a limitação da carga horária (aula de 45 minutos).

Esse item para os estudantes ficou da seguinte forma: "[...] gostaria que a professora fizesse mais trabalhos em grupo, porque assim um pode ajudar o outro, mas ela acaba fazendo poucos trabalhos, pois temos poucas aulas também" (Aluno A). Praticamente a grande maioria dos estudantes entrevistados não emitiu sugestões sobre avaliação em Arte, o que nos leva a refletir sobre certa passividade, acomodação ao que já está posto.

Também percebemos que as relações entre os aspectos cognitivos e as relações afetivas acabam contribuindo para essa aceitação, ou seja, as boas relações que os estudantes têm com os professores de Arte impedem que eles tenham discernimento entre as construções afetivas, os processos de aprendizagem e a crítica. Sugerir ou criticar as aulas de Arte, para os estudantes, significa magoar e/ou constranger os professores.

Ainda outra questão que nos causa preocupação: a voz dos estudantes pouco é ouvida. As ações, seja em planos ou projetos pedagógicos, são definidas sempre pelos professores ou pela gestão escolar.

Com relação à ausência de livros específicos de Arte nas bibliotecas escolares, entendemos que o fato compromete as questões de ensino e aprendizagem e, consequentemente, a avaliação, o que nos leva às seguintes reflexões: o professor de Arte tem por premissa fundamentar as questões de ensino na literatura específica da área? Esses livros são solicitados pelos professores? As escolas consideram esse material de alto custo e por isso não os adquire?

Aqui é importante destacar que não estamos nos referindo a livros didáticos, mas, sobretudo, a livros que tratam das relações da arte com o conhecimento, a filosofia, a antropologia, a estética, os processos de criação e as questões propriamente artísticas. Também são necessários livros que abordem questões relativas à arte/educação e suas principais tendências na atualidade. A realidade apontada pela maioria dos professores interessados é de que as bibliotecas escolares estão carentes de livros que tratam da arte e da arte/educação, o que nos leva a pensar que um problema está ligado a outro, ou seja, a falta de acesso à literatura pode implicar uma prática destituída de reflexão teórica.

Com relação à inexistência de espaço ou sala específica para a Arte nas escolas, cabe considerar que a estrutura e o arranjo dos espaços escolares refletem culturas, filosofias e escolhas ali estabelecidas, favorecendo ou não a aprendizagem. O contexto arquitetônico e funcional dos espaços escolares está integrado ao plano de ações educativas e com o Projeto Políticopedagógico da escola. Ali os objetos, os materiais, as estruturas não são elementos passivos, mas interferem na estrutura cognitiva e afetiva dos estudantes, assim como refletem valores, ideias e culturas na escola e da escola.

Viñao Frago e Escolano (2001) fazem uma interessante reflexão sobre a dimensão simbólica dos espaços escolares. Segundo os autores, todo espaço é um lugar percebido e assim é um processo cultural, ético, estético e ideológico de representações. Portanto, o espaço 
arquitetônico expressa um sistema de intenções, discursos, valores e discursos, constituído de signos e simbolismos. Nessa perspectiva, o espaço nunca será neutro e sempre terá um viés educativo. Para Escolano (2001), os espaços subjetivos presentes na arquitetura escolar partem da concepção de que o espaço escolar expressa e reflete determinados discursos, sendo uma fonte de experiência e de aprendizagem.

Todavia, como as salas de aula ou laboratórios de arte estão dispostos, o tipo e a organização de carteiras, mesas e demais móveis escolares e os tempos alocados a cada disciplina também não são elementos neutros na educação. Todos esses aspectos, incluindo detalhes de organização dos móveis e objetos, devem ser considerados como parte do currículo escolar, uma vez que correspondem a "padrões culturais e pedagógicos que a criança internaliza e aprende" (ESCOLANO, 2001, p. 45).

Para Cunha (2008), a dimensão humana pode modificar o espaço em espaço/lugar. O lugar se constitui quando atribuímos sentido aos espaços, ou dizendo de outra forma, quando reconhecemos sua legitimidade para localizar ações, expectativas, inquietações, dúvidas, esperanças e possibilidades. Ao dizermos "esse lugar é de", vamos além da condição de espaço, atribuindo um sentido cultural e subjetivo.

Os lugares extrapolam uma base física e espacial para assumir uma condição cultural, humana e subjetiva. Entram em jogo as representações que os sujeitos fazem dos lugares e o sentido que atribuem aos mesmos. (CUNHA, 2008, p. 184).

$\mathrm{Na}$ visão de Lima (1995, p. 187), o espaço é vital para o desenvolvimento humano e para as suas construções identitárias. Além de ser "[...] um elemento potencialmente mensurável, é o lugar de reconhecimento de si e dos outros porque é no espaço que ele se movimenta, realiza atividades e estabelece relações sociais".

Paralelamente à questão dos espaços na escola está a limitação de tempo de aula para a disciplina de Arte. Segundo a maioria dos professores, aulas de 45/50 minutos dificultam abordagens que articulem o fazer, o ler e o pensar. A pesquisa aponta a fragmentação disciplinar como aspecto redutor no currículo, desdobrando-se na avaliação.

Por vezes, A escola controla, separa, analisa, diferencia e regula os estudantes que são constantemente configurados, enquadrados, adaptados (FOUCAULT, 1989). O estudante não é mobilizado a conquistar o seu espaço, a utilizar o seu tempo, e sim a aceitar imposições e regras preestabelecidas das quais ele não sabe por quem nem por que foi constituída e instituída. $\mathrm{O}$ espaço e o tempo na escola, para Foucault (1989, p. 149), “[...] são usados como operadores de adestramento", que se inspiram no modelo militar.

Por fim, sobre as políticas de avaliação, os professores afirmaram que a rede e a escola evidentemente se apropriam dos conceitos e das metodologias dos Parâmetros Curriculares Nacionais (BRASIL, 1998). No entanto, quando perguntamos quais as principais concepções e orientações do documento em relação à avaliação, não responderam, o que nos leva a presumir que essa intenção fica apenas no corpo teórico sem chegar às práticas educativas propriamente ditas.

Sobre as questões teórico-conceituais do PCN, a grande maioria dos professores entrevistados entende o documento como sinalizador de "[...] critérios de avaliação, tendo papel importante nos processos curriculares [...]" (BRASIL, 1997, p. 58). Compreendem também que os PCN apontam expectativas de aprendizagem, considerando objetivos e conteúdos propostos para a área, bem como as possibilidades de "[...] aprendizagem decorrentes de cada etapa do desenvolvimento cognitivo, afetivo e social em uma determinada situação, na qual os alunos

Práxis Educativa, Ponta Grossa, p. 757-774, v. 11, n. 3, set./dez. 2016 Disponível em: <http://www.revistas2.uepg.br/index.php/praxiseducativa $>$ 
tenham boas condições de desenvolvimento do ponto de vista pessoal e social" (BRASIL, 1997, p. 58).

A pesquisa reiterou, com base nos estudos e leitura e especialmente nas entrevistas dos professores que, embora as redes de ensino, as escolas e os professores tentem praticar uma avaliação mais democrática e significativa, ainda estão atrelados a um sistema educacional disciplinar, sequencial e fragmentado, reduzindo significativamente tal prática.

\section{Últimas considerações}

A análise dos resultados nos faz refletir sobre a formação dos professores de Arte, as suas condições de trabalho, o reconhecimento social da disciplina. Esses aspectos estão relacionados à forma como as políticas, nesse caso de avaliação, são incorporadas ao currículo na escola. Verificamos que a avaliação é vista pelos professores ora como parte do processo de aprendizagem, ora como elemento limitador, que sinaliza aprovação ou reprovação do estudante e algumas vezes como um fragmento isolado do currículo.

No que se refere às questões do currículo, é importante refletir sobre a afirmação de Goodson (2001, p. 251) quando diz que, "no novo futuro social, devemos esperar que o currículo se comprometa com as missões, paixões e propósitos que as pessoas articulam em suas vidas".

A avaliação nessa tendência segue na mesma perspectiva, ou seja, leva em conta a trajetória de aprendizagem de cada estudante, respeitando suas singularidades e sua inserção na coletividade, identificando seus modos de aprender sobre Arte, do ponto de vista cognitivo, sensível e cultural. Isso significa, por parte do professor, um olhar apurado sobre aqueles conhecimentos e saberes trazidos pelos estudantes e o que é necessário que eles aprendam para além desses saberes, que poderão melhor qualificar suas vidas. Em outras palavras, quando tomamos decisões no campo da avaliação, é preciso refletir sobre as contribuições desse processo para o gerenciamento de vida dos estudantes e qual o sentido do que aprendem para os desdobramentos de suas vidas no campo pessoal, profissional e, sobretudo, afetivo.

O professor de Arte nessa abordagem pode provocar situações de aprendizagem, de afetamentos e apropriação de conceitos e de diálogo com a vida, mobilizando a ação/reflexão, a pesquisa dos estudantes e a procura de novas aprendizagens.

Barbosa (2009, p. 22), sobre a avaliação, também nos alerta para a necessidade de ampliar nossos conceitos para além de termos como erros e acertos, especialmente na disciplina de Arte. Afirma a autora que "é preciso descobrir os erros para não repeti-los, e eles são descobertos mediante avaliação, que não deve levar à punição... mas, à readequação, reestruturação, redimensionamento".

Essas questões merecem ser consideradas e demandam contínuos debates no âmbito da epistemologia da Arte/educação. Vale ressaltar que o processo avaliativo em Arte também está vinculado à relação inclusão/exclusão escolar e social e que nesse campo de conhecimento os modelos hegemônicos de avaliação estão alinhados às concepções excludentes de relações sociais e práticas pedagógicas. Como diz Barbosa (2009, p. 22), "é pelo caminho da pesquisa e da avaliação que se pode desenvolver o enorme potencial educativo... para o entendimento do mundo eu nos cerca...".

Portanto, entender a avaliação como processo contínuo de aprendizagem é pensar em ações que dão espaço ao conhecimento, ao sensível, à construção cultural e a um sujeito crítico e partícipe do contexto social. É, acima de tudo, viver uma educação humanitária que contribua 
para a constituição de seres criativos, justos, cientes do seu papel na sociedade. É também estarmos inseridos nas políticas públicas de educação, especialmente nas que apontam caminhos para a avaliação. Talvez de forma compartilhada possamos romper com alguns resquícios sobre avaliação e avançarmos para um processo que garanta a articulação entre ensino, aprendizagem e avaliação.

Nesse foco, é possível ter consciência de nossos esforços ou não, de nossos descaminhos, desencontros e também de nossos méritos com relação aos métodos avaliativos. Entendemos que a ação avaliadora é parte do processo de aprendizagem e conhecimentos, bem como de nossa habilidade e sensibilidade em utilizá-los. A avaliação, portanto, pode ser compreendida como trajeto que trilhamos dia a dia, no intuito de estarmos presente nesse infinito jogo de ensinar e aprender (DUARTE JÚNIOR, 2001).

A pesquisa nos mostrou que nas trajetórias curriculares e, nesse contexto, no currículo não existem fórmulas mágicas que apontem caminhos certos e definitivos. Existe sim uma vontade imensa de acertar o passo, mesmo no descompasso. Nesses caminhos existem variáveis: sistemas educativos, concepções apropriadas por redes de ensino e escolas, leis que tramitem, documentos e políticas públicas que direta ou indiretamente podem interferir em nossas práticas educativas e consequentemente avaliativas.

$\mathrm{O}$ artigo aqui socializado, mais do que julgar os procedimentos utilizados pelos professores de Arte ou apontar métodos para a avaliação, pretende refletir com o leitor sobre os desdobramentos das políticas de avaliação nas práticas educativas na disciplina de Arte. Evidentemente muitas das questões identificadas nessas vozes também se encontram em outras vozes de professores que atuam em outras disciplinas.

No entanto, pela história de lutas da inclusão da Arte no currículo e pelo esforço dos professores em mantê-la no currículo, bem como pelos equívocos conceituais descritos nesse artigo sobre a real função da disciplina no currículo, faz-se necessário o pensar sobre como está sendo conduzida e quais as perspectivas futuras da Arte no currículo. Chegamos à conclusão de que os caminhos percorridos no currículo são acompanhados de políticas de avaliação e das decisões tomadas por nós, partícipes desses processos.

A pesquisa, para além da contribuição científica, nos proporcionou a ampliação do olhar para as questões referentes às políticas de avaliação e às práticas educativas dos professores de Arte, o que nos levou à autoavaliação na perspectiva de olhar nossas práticas avaliativas e nossas ações com base nas políticas públicas e no que nos impulsiona a continuarmos trilhando caminhos nessa significativa jornada que é ser professor.

\section{Referências}

ALVES, M. P. C. O desenvolvimento do currículo e a avaliação por competências. In: LOPES, A. R. C.; MACEDO, E. F.; ALVES, M. P. C. (Orgs.). Cultura e política de currículo. Araraquara: Junqueira \& Marin, 2006. p. 161-179.

BARBOSA, A. M. Mediação cultural é social. In: BARBOSA, A. M.; COUTINHO, R. G. (Orgs.). Arte/educação como mediação cultural e social. São Paulo: Editora UNESP, 2009. p. 13-22.

BARBOSA, A. M.; COUTINHO, R. G. (Orgs.). Arte/educação como mediação cultural e social. São Paulo: Editora UNESP, 2009. 
BOUGHTON, D. Avaliação: da teoria à prática. In: BARBOSA, A. M. (Org.). Arte/educação contemporânea: consonâncias internacionais. São Paulo: Cortez, 2005. p. 375-420.

BRASIL. Lei n. ${ }^{\circ}$ 5.692, de 11 de agosto de 1971. Fixa diretrizes e bases para o ensino de $1 .^{\circ}$ e 2. ${ }^{\circ}$ graus, e dá outras providências. Revogada pela Lei n. ${ }^{\circ}$ 9.394/96.

BRASIL. Lei de Diretrizes e Bases da Educação Nacional. Lei n. ${ }^{\circ}$ 9.394, 20 de dezembro de 1996.

BRASIL. Secretaria de Educação Fundamental. Parâmetros Curriculares Nacionais: Secretaria de Educação Fundamental. - Brasília: MEC/SEF, 1997.

BRASIL. Secretaria de Educação Fundamental. Parâmetros curriculares nacionais: arte / Secretaria de Educação Fundamental. - Brasília: MEC / SEF, 1998. 116 p.

BRASIL. Ministério da Educação. Secretaria de Educação Básica. Secretaria de Educação Continuada, Alfabetização, Diversidade e Inclusão. Secretaria de Educação Profissional e Tecnológica. Diretoria de Currículos e Educação Integral. Conselho Nacional da Educação. Câmara Nacional de Educação Básica. Diretrizes curriculares nacionais gerais da educação básica. Brasília, 2013. 562 p.

CANDAU, V. M. (Coord.). Somos todos iguais? Escola, discriminação e educação em direitos humanos. Rio de Janeiro: DP\&A, 2003. 176 p.

CUNHA, M. I. da. Os conceitos de espaço, lugar e território nos processos analíticos da formação dos docentes universitários. Revista Educação UNISINOS, São Leopoldo, v. 12, n. 3, p. 182 - 183, set./dez. 2008. DOI: 10.4013/edu.20083.03

DUARTE JR., J. F. O sentido dos sentidos - a educação (do) sensível. Curitiba: Criar Edições, 2001.

EISNER, E. W. El ojo ilustrado. Buenos Aires: Paidós, 1998.

ESCOLANO, A. La arquitectura como programa. Espacio-Escuela y currículum in Historia de la educación. Salamanca: Edições Universidade de Salamanca, 1993-4.

ESCOLANO, A. Arquitetura como programa: espaço-escola e currículo. In: VIÑAO FRAGO, A.; ESCOLANO, A. Currículo, espaço e subjetividade: a arquitetura como programa. Tradução de Alfredo Veiga-Neto. 2. ed. Rio de Janeiro: DP\&A, 2001. p. 19-57.

ESTEBÁN, M. T. (Org.). Escola, currículo e avaliação. 2. ed. São Paulo: Cortez, 2005.

FERRAZ, M. H. C. T; FUSARI, Maria F. R. Metodologia do ensino de arte: fundamentos e proposições. 2. ed. São Paulo: Cortez, 2009.

FERREIRA, C. O.; BOFF, C. E. Autoavaliação: um caminho responsável nesse andar formativo. In: PILLOTTO, S. S. D.; ALVES, M. P. C. (Orgs.). Avaliação em educação: questões, tendências e modelos. Joinville: Editora Univille, 2009.

FLICK, U. Uma introdução à pesquisa qualitativa. 2. ed. Porto Alegre: Bookman, 2004. 
FORQUIN, J. C. Escola e cultura: as bases sociais e epistemológicas do conhecimento escolar. Porto Alegre: Artes Médicas, 1993.

FOUCAULT, M. Vigiar e punir: a história da violência nas prisões. Petrópolis: Vozes, 1989.

GATTI, B.; ANDRÉ, M. A relevância dos métodos de pesquisa qualitativa em educação no Brasil. In: WELLER, W.; PFAFF, N. (Orgs.). Metodologias de pesquisa qualitativa em educação - teoria e prática. Petrópolis: Vozes, 2010. p. 29-38.

GOODSON, I. O currículo em mudança: estudos na construção social do currículo. Porto: Porto, 2001.

HALL, S. A identidade cultural na pós-modernidade. São Paulo: DP\&A, 2007.

HERNÁNDEZ, F. Catadores da cultura visual: proposta para uma nova narrativa educacional. Porto Alegre: Mediação, 2007.

LIMA, M. W. S. Arquitetura e educação. São Paulo: Studio Nobel, 1995.

MACEDO, E. Currículo e competência. In: LOPES, A. C.; MACEDO, E. (Orgs.). Disciplinas e integração curricular: história e políticas. Rio de Janeiro: DP\&A, 2002.

MARTINS, M.; GUERRA, M. T. Didática do ensino de arte - a língua do mundo: poetizar, fruir e conhecer arte. São Paulo: FTD, 1998.

MARTINS, M. C. F. D.; PICOSQUE, G.; GUERRA, M. T. T. Teoria e prática do ensino de arte: a língua do mundo. São Paulo: FTD, 2009.

MINAYO, M. C. de S.; SANCHES, O. Quantitativo-qualitativo: oposição ou complementaridade? Cadernos de Saúde Pública, Rio de Janeiro, v. 9, n. 3, p. 239-262, 1993.

MOREIRA, A. F.; CANDAU, V. M. Educação escolar e cultura(s): construindo caminhos. Revista Brasileira de Educação, Rio de Janeiro, n. 23, p. 156-168, maio/ago. 2003. DOI: 10.1590/S1413-24782003000200012

MORGADO, J. C. Formação e desenvolvimento profissional docente: desafios contemporâneos. Cadernos CIEd, Braga, v. 1, n. 1, p. 41-57, 2007.

PETITAT, A. Produção da escola/produção da sociedade: análise sócio-histórica de alguns momentos decisivos da evolução escolar no ocidente. Tradução de Eunice Gruman. Porto Alegre: Artes Médicas, 1994.

PILLAR, A. D. (Org.). A educação do olhar no ensino das artes. Porto Alegre: Mediação, 2006. p. 9-21.

PIMENTEL, L. G. Limites em expansão: licenciatura em artes visuais. Belo Horizonte: C/Arte, 1999.

SANT'ANNA, I. M. Por que avaliar? Como avaliar? critérios e instrumentos. Petrópolis: Vozes, 2010. 
SANTA CATARINA. Secretaria de Estado da Educação e do Desporto. Proposta curricular de Santa Catarina: educação infantil, ensino fundamental e médio: disciplinas curriculares. Florianópolis: COGEN, 1998.

SANTA CATARINA. Governo do Estado. Secretaria de educação básica Proposta curricular de Santa Catarina. Florianópolis, 2014. 192 p.

SILVA, T. T. da. Documentos de identidade: uma introdução às teorias do currículo. Belo Horizonte: Autêntica, 1999.

VEIGA-NETO, A.; WORTMANN, M. L. C. Estudos culturais da ciência \& educação. Belo Horizonte: Autêntica, 2001 (Coleção temas \& educação).

VIÑAO FRAGO, A.; ESCOLANO, A. Currículo, espaço e subjetividade: a arquitetura como programa. Tradução de Alfredo Veiga-Neto. 2. ed. Rio de Janeiro: DP\&A, 2001.

Recebido em 21/11/2015

Aceito em 24/05/2016 